
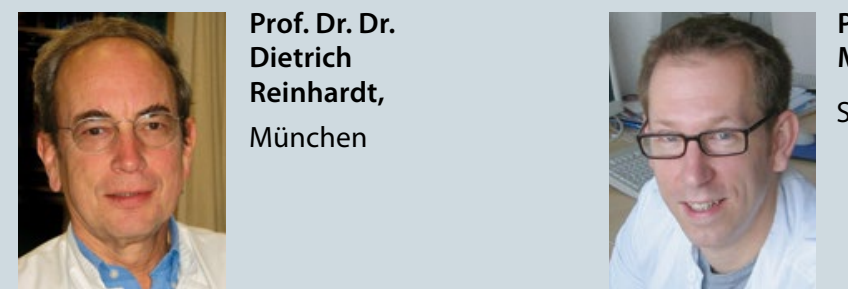

Prof. Dr. med.

Martin Storr,

Starnberg

\section{Die Glutensensitivität gibt es wirklich}

\section{Seit einigen Jahren etabliert sich der Begriff der Glutensensitivität, genauer: der Nicht-Zöliakie-nicht-Weizenallergie-Weizensensitivität. Eine Studie liefert nun Beweise für die Existenz des Krankheitsbildes.}

$\mathrm{D}$ ie sogenannte Glutensensitivität ist momentan in aller Munde und wird in Fachkreisen kritisch diskutiert. Auch wird der Begriff seit einiger Zeit vermehrt in Leitlinien und Expertengremien verwendet. Er kommt immer dann zum Einsatz, wenn nach Glutenkonsum verifizierbare gastrointestinale $\mathrm{Be}$ schwerden bestehen, die sich unter einer glutenfreien Diät verbessern. Bei den Patienten sind eine Zöliakie wie auch eine Weizenallergie sicher ausgeschlossen.

Die Aufmerksamkeit gegenüber der Glutensensitivität ist bei den Patienten derzeit größer als gegenüber der Zöliakie. Dies lässt sich mit Sicherheit auf die Berichterstattung mancher Medien und die Kommunikation in sozialen Netzwerken zurückführen, wo der Konsum von Gluten und Getreideprodukten momentan verbreitet als schädlich dargestellt wird.

Eine aktuelle, kontrollierte klinische Studie ist der Frage nachgegangen, in welchem Ausmaß kleine Mengen von Gluten bei Patienten mit einer vermuteten Glutensensitivität intestinale und extraintestinale Beschwerden verursachen. Um diese Frage zu beantworten, wurde in der randomisierten, doppelblinden Studie ein placebokontrolliertes Crossover-Protokoll verwendet. Nach Ausschluss einer Zöliakie, einer Weizenall- ergie und anderer möglicher Ursachen der Beschwerden erhielten die Patienten mit der vermuteten Glutensensitivität eine glutenfreie Diät. Daneben sollten sie für jeweils eine Woche verkapseltes Gluten in kleiner Menge $(4,4 \mathrm{~g})$ oder als Placebo verkapselte Reisstärke einnehmen.

Die einwöchige Glutenexposition führte zu einer signifikanten Zunahme von abdominellen Schmerzen, Blähungen, depressiver Stimmungslage, Aphthen an der Mundschleimhaut und Benommenheit.

Di Sabatino A et al. Small amounts of gluten in subjects with suspected nonceliac gluten sensitivity: A randomized, double-blind, placebo-controlled, cross-over trial. Clin Gastroenterol Hepatol 2015;13:1604-12

\section{Kommentar}

In Anbetracht der zahlreichen Patienten, die bei sich eine Glutensensitivität vermuten, ist diese Studie bemerkenswert. Sie wurde explizit nicht an Patienten mit einem Reizdarmsyndrom durchgeführt, sondern an Patienten, bei denen vorab das Bestehen einer Glutensensitivität klinisch vermutet wurde. Dass in einer auf diese Weise vorselektierten Patientengruppe kleine Mengen von Gluten tatsächlich intestinale und extraintestinale Beschwerden verschlimmern, ist ein eindrucksvoller Beleg dafür, dass das Krankheitsbild der Glutensensitivität durch-

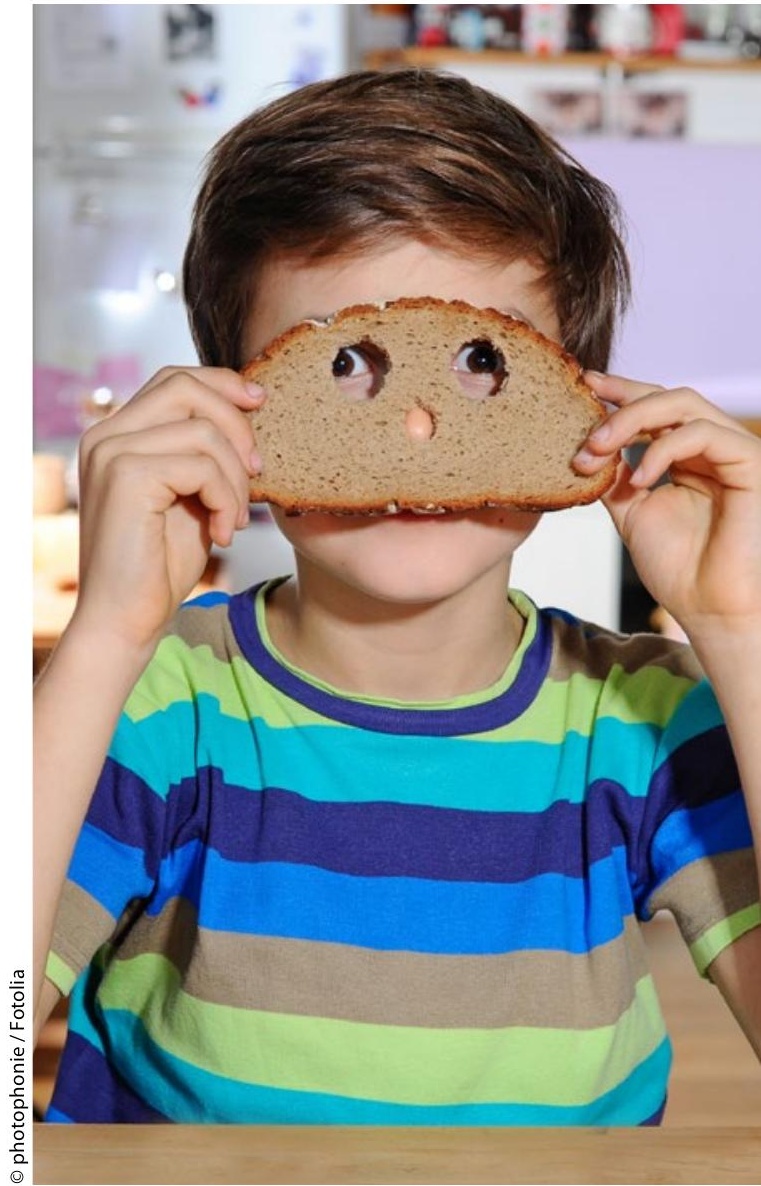

Die nicht Zöliakie-bedingte Glutenunverträglichkeit - kurz: Glutensensitivität - steht immer mehr unter Beobachtung.

aus ein reales ist. Da mag es aktuell verschmerzbar sein, dass die Pathophysiologie der Glutensensitivität bisher noch nicht wissenschaftlich geklärt werden konnte.

Prof. Dr. Martin Storr 